\title{
DOEGE-POTTER Syndrome in Malignant Neurofibromatous Tumor: A Case Report
}

\author{
Yassine El Ouai ${ }^{1 *}$, V Litique ${ }^{2}$, C Iltis ${ }^{2}$, K Oualla ${ }^{1}$, Z benbrahim ${ }^{1}$, L Amaadour ${ }^{1}$, S Arifi ${ }^{1}$, JM Li- \\ macher $^{2}$ and N Mellas ${ }^{1}$ \\ ${ }^{1}$ Medical Oncology department, Hassan II University Hospital Center, Morocco
}

${ }^{2}$ Onco-Hematology department, Louis Pasteur Hospital Center, France

*Corresponding author: Yassine El Ouai, Medical Oncology department, Hassan II University Hospital Center, Fez, Morocco.

To Cite This Article: Yassine El Ouai, V Litique, C Iltis, K Oualla, Z benbrahim, et al. DOEGE-POTTER Syndrome in Malignant Neurofibromatous Tumor: A Case Report. Am J Biomed Sci \& Res. 2021 - 12(4). AJBSR.MS.ID.001770. DOI: 10.34297/AJBSR.2021.12.001770.

Received: 眥 April 09, 2021; Published: 眥 April 19, 2021

\begin{abstract}
DOEGE-POTTER syndrome is a paraneoplastic syndrome in which hypoglycemia results from tumors producing insulin-like growth factor (IGFII). It is most often the solitary fibrous tumor of the pleura. These are rare and may be discovered incidentally, during non-specific respiratory symptoms or during hypoglycemia. Hypoglycemia occurs in large tumors and disappears after surgery, which is the treatment of choice, allowing permanent cure in the majority of cases.
\end{abstract}

We report the case of a 61-year-old patient followed in Pasteur Hospital for a local recurrent malignant neurofibromatous tumor presenting recurrent hypoglycaemia with hypersecretion of insulin-like growth factor.

\section{Introduction}

DOEGE-POTTER syndrome is a rare paraneoplastic syndrome, initially described in 1930 by Doege and Potter and mainly involving solitary pleural fibrous tumors. Hypoglycemia is an infrequent complication of these tumors, via an insulin-like growth factor secretion mechanism, and may be indicative of it. These tumors have a low rate of malignancy, around $12 \%$ to $15 \%$.

\section{Case Report}

We report the case of a 61-year-old patient followed for solitary fibrous tumor of the pleura who underwent video-thoracoscopic resection in 2009, then remained under surveillance. Eleven years later, the patient presented with a local relapse, cancer surgery was not possible, hence the initiation of sunitinib.

The patient was hospitalized for hypoglycaemia associated with recurrent malaise, the diagnosis of para-neoplastic hypoglycemia (DOEGE-POTTER syndrome) was retained with hypersecretion of BIG-IGF.

\section{Discussion}

Neurofibromatous tumors are rare spindle cell neoplasms first described clinically in 1870 by Wagner [1] and then described histopathologically by Klemperer and Rabin in 1931 [2]. DoegePotter syndrome is a paraneoplastic condition defined by NICTH secondary to neurofibromatous tumors; this occurs in less than $5 \%$ of neurofibromatous tumors cases [3-5].

The typical mechanism of hypoglycemia with neurofibromatous tumors involves tumor production of a prohormone form of IGF-II, often referred to as "big IGF-II" [6]. Big IGF-II causes hypoglycemia by multiple mechanisms [7-9]. The insulin-like effects of large IGFII cause increased uptake of glucose by insulin-sensitive tissues, especially muscle and fat, but it may also stimulate uptake of glucose by the body tumor itself. Decreased hepatic glucose production may also be related to the insulin effect of large IGF-II, and glucagon secretion may also be low in NICTH. 
However, the IGF-II : IGF-I molar ratio is considered to be a surrogate marker for the high concentration of IGFII [8]. In NICTH, IGF-II provides central negative feedback from growth hormone, with subsequent reduction in IGF-I production. This contributes to an increase in the IGF-II: IGF-I ratio; a ratio of 3: 1 is considered normal, with a ratio greater than 10 being practically pathognomonic for NICTH [10]. Decreased growth hormone secretion also leads to lower concentrations of IGF-binding proteins, which may increase the bioavailability of IGF-II [7].

Symptoms attributable to hypoglycemia should be present, primarily confusion, drowsiness, or inappropriate sweating. Of the cases reported worldwide, $50 \%$ are mild and $50 \%$ have a malignant transformation [11]. Malignant diagnoses predominate in people diagnosed between the ages of 50 and 70 .

Computed tomography is of the greatest preoperative diagnostic value in intrathoracic neurofibromatous tumors and their presentation in this modality is well documented [12].

Blood tests at the time of hypoglycemia in these patients show a high IGF-II : IGF-I ratio (indicating high IGF-II) and low insulin concentration. The additional physiological concentration of this IGF-II leads to inappropriate activation of systemic insulin receptors. The resulting hypoglycemia can be fatal if permanent surgery is not performed [11-13].

Neurofibromatous tumors are mesenchymal neoplasms of unknown derivation; they are generally of thoracic origin but extrathoracic cases are also observed [13]. The postoperative risk of recurrence or metastasis increases with a tumor size $>10 \mathrm{~cm}$ or if a malignant component is detected. Treatments and results depend on the histological grade and stage of the tumor. Benign lesions are best treated with simple resection and complete resection prevents further hypoglycaemic episodes. Malignant lesions require complex en bloc resection of the tumor and adherent tissue. In histological analysis after resection or in cases where surgical treatment is not likely to be possible for the patient, radiotherapy and chemotherapy have been described for treatment and palliative care, but with prognostic impact uncertain [13].

\section{Conclusion}

DOEGE-POTTER syndrome is a rare entity which should be considered when episodes of hypoglycemia occur. The post-surgical follow-up of these patients must be regular in view of the risk of tumor recurrence. Although rare, tumor-induced hypoglycemia should be considered the primary differential diagnosis in a patient with known chest malignancy given the important consequences of this condition if left untreated.

\section{References}

1. Wagner E (1870) Das tuberkelahnliche lymphadenom (der cytogene oder reticulirte tuberkel). Arch Heilk 11: 497.

2. Klemperer P, Rabin CB (1931) Primary neoplasm of the pleura: a report of five cases. Arch Pathol 11: 385-412.

3. Doege KW (1930) Fibrosarcoma of the mediastinum. Ann Surg 92: 955961.

4. Potter RP (1930) Intrathoracic tumours. Case report. Radiology 14(1): 60-61.

5. Briselli M, E J Mark, G R Dickersin (1981) Solitary fibrous tumors of the pleura: eight new cases and review of 360 cases in the literature. Cancer 47(11): 2678-2689.

6. Hajdu M, Singer S, Maki RG, Schwartz GK, Keohan ML (2010) Antonescu CR: IGF2 over-expression in solitary fibrous tumours is independent of anatomical location and is related to loss of imprinting. J Pathol 221: 300-307.

7. Le Roith D (1997) Seminars in medicine of the Beth Israel Deaconess Medical Center. Insulin-like growth factors. N Engl J Med 336: 633-640.

8. Marks V, Teale JD (1998) Tumours producing hypoglycaemia. EndocrineRelated Cancer 5: 111-129.

9. Hoff AO, R Vassilopoulou-Sellin (1998) The role of glucagon administration in the diagnosis and treatment of patients with tumor hypoglycemia. Cancer 82: 1585-1592.

10. Teale JD, Marks V (1990) Inappropriately elevated plasma insulin-like growth factor II in relation to suppressed insulin-like growth factor I in the diagnosis of non-islet cell tumour hypoglycaemia. Clin Endocrinol (Oxf) 33: 87-98.

11. Meng W, Zhu HH, Li H, Guoqing Wang, Dongshan Wei, et al. (2014) Solitary fibrous tumors of the pleura with Doege-Potter syndrome: a case report and three-decade review of the literature. BMC Res Notes 7: 515.

12. Wignall OJ, Moskovic EC, Thway K, Thomas JM (2010) Solitary fibrous tumors of the soft tissues: review of the imaging and clinical features with histopathologic correlation. Am J Roentgenol 195(1): W55-W62.

13. Schutt RC, Gordon TA, Bhabhra R, Helen P Cathro,3 Stephen L Cook, et al. (2013) Doege-Potter syndrome presenting with hypoinsulinemic hypoglycemia in a patient with a malignant extrapleural solitary fibrous tumor: a case report. J Med Case Rep 7: 11. 